\title{
Endocrinologia \\ EM QUE CENÁRIO OCORRE A ATUAL REVISÃO DA DECLARAÇAO DE HELSINQUE?
}

A Declaração de Helsinque é um documento internacionalmente reconhecido como âncora da ética em pesquisa em seres humanos, desde sua publicação original, em 1964, pela World Medical Association (WMA). Desde então, passou por cinco revisões e duas notas de esclarecimento, buscando atualização contínua, à luz da evolução do conhecimento científico. Em 2007, o Conselho da WMA autorizou uma nova revisão e, em agosto de 2008, o Brasil teve a oportunidade de sediar, em São Paulo, uma reunião da WMA com este objetivo. A aprovação final será feita na Assembléia Geral da WMA, em outubro de 2008. Três temas principais estão em discussão: a pesquisa clínica em crianças, o uso de placebo em pesquisa clínica e o acesso ao medicamento após o encerramento da pesquisa. 0 evento foi aberto à comunidade científica brasileira que, por dois dias, participou ativamente de discussões apaixonadas sobre cada um dos tópicos ${ }^{1}$.

A maior parte dos medicamentos utilizados em pediatria nunca foi testada. Visando-se proteger as crianças de ambientes experimentais, os medicamentos são, muitas vezes, incorporados ao arsenal terapêutico sem a avaliação específica nesta faixa etária. A questão que fica é se não é pior utilizar um novo medicamento em crianças sem tê-lo testado adequadamente nesta população, uma vez que, em um ambiente de pesquisa clínica, o controle é muito mais rigoroso e planejado, de modo a identificar precocemente qualquer problema. Outra questão relacionada é quem deve conceder o consentimento? Os pais, a criança, ambos? E, no caso de adolescentes, esta questão do consentimento é ainda mais difícil de responder.

Quanto ao uso do placebo em pesquisa, sabe-se que, embora bem justificado em algumas situações específicas, como é o caso de algumas patologias psiquiátricas, longas discussões são travadas no que concerne à ética destas pesquisas. Duas situações são claras: no caso de patologia séria, com tratamento disponível, o uso de placebo é antiético e não deve ser usado; por outro lado, em patologias onde não 
existe tratamento efetivo conhecido, o placebo deve ser usado. A própria Resolução do CNS 196/96 (item III.3) cita: deve-se "ter plenamente justificada, quando for o caso, a utilização de placebo, em termos de não-maleficência e de necessidade metodológica". Alguns critérios devem ser considerados: a ética deve prevalecer sobre a metodologia, o uso de placebo não pode levar risco adicional ao paciente, deve haver aprovação prévia do comitê de ética em pesquisa da instituição e assinatura do consentimento antes de qualquer procedimento do estudo. Adicionalmente, o paciente pode se retirar a qualquer momento do estudo e receber droga ativa, sendo que o menor número possível de pacientes deve ser incluído no grupo placebo e pelo menor período possível².

E o que fazer ao final do estudo, no que concerne à questão de acesso ao medicamento do estudo? Esta pergunta é particularmente crítica em países em desenvolvimento e em patologias crônicas, onde a garantia de acesso após o estudo pode ser essencial. Entretanto, pode também conduzir à indução à participação na pesquisa indevidamente, devido ao benefício assegurado. Além de se pensar no benefício ao paciente de pesquisa, deve-se ter em mente os possíveis riscos de se manter um medicamento ainda não aprovado ou liberado para uso clínico. Certamente, a conduta deve ser definida antes do início da pesquisa clínica e estar descrita no protocolo, de modo a ter a prévia aprovação do comitê de ética.

Neste cenário e assumindo postura no mínimo polêmica, o FDA (Food and Drug Administration) anunciou adotar, a partir de outubro de 2008, o GCP/ICH (Good Clinical Practices / International Conference on Harmonization, 1996) como novo padrão para pesquisas com seres humanos, em substituição à Declaração de Helsinque. Embora o GCP lide com o tema de proteção aos pacientes, ele não é um documento de direitos humanos e sim um documento de metodologia de condução de pesquisa $^{3}$. Determinar o ponto ótimo de relacionamento entre a saúde pública e a saúde do indivíduo é, sem dúvida, um grande desafio ético. Desde sua adoção em 1964, a Declaração de Helsinque teve, como objetivo, prover diretrizes aos médicos envolvidos em pesquisa clínica e seu principal foco está nas responsabilidades dos pesquisadores na proteção aos participantes da pesquisa. Desde a revisão de 2000 , entretanto, maior preocupação com saúde pública vem sendo observada. Mesmo assim, prevalece ainda o conceito de que o bem estar dos indivíduos deve prevalecer sobre os interesses da ciência e da sociedade ${ }^{4}$.

Referências

1.Declaração de Helsinque: revisão no Brasil. J ornal AM B. 2008;49 (1354):811. Disponível em: http://www.amb.org.br.

2.Fineberg NA, Gale TM, Hawley CJ . Is there place for placebo controlled trials in the treatment of affective disorders? Rev Bras Psiquiatr. 2006, 28(2):89 90. Available from: http://www.scielo. br/pdf/rbp/v28n2/29772.pdf.

3.Editorial. Trials on trial. The FDA should rethink its rejection of the Declaration of Helsinki. Nature. 2008;453(7194):427-28. Available from: http://www. nature.com/nature/journal/v453/n7194/full/453427b.html.

4.Williams J R. The DoH and public health. Bull WHO. 2008, 86(8):650-51. Available from: http://www. who.int/bulletin/volumes/86/8/08-050955.pdf.

Doutoranda na Faculdade de Medicina da USP

Sonia Mansoldo DainesI ${ }^{1}$

Diretora Médica da Boehringer Ingelheim do Brasil, São Paulo, SP

\section{Correspondência:}

Rua Ribeiro Lisboa 165

Morumbi - São Paulo - SP 